\title{
Truthmaking and Fundamentality
}

DOI:

10.1111/papq.12082

\section{Document Version}

Submitted manuscript

Link to publication record in Manchester Research Explorer

\section{Citation for published version (APA):}

Fisher, A. R. J. (2016). Truthmaking and Fundamentality. Pacific Philosophical Quarterly, 97(4), 448-73. https://doi.org/10.1111/papq.12082

\section{Published in:}

Pacific Philosophical Quarterly

\section{Citing this paper}

Please note that where the full-text provided on Manchester Research Explorer is the Author Accepted Manuscript or Proof version this may differ from the final Published version. If citing, it is advised that you check and use the publisher's definitive version.

\section{General rights}

Copyright and moral rights for the publications made accessible in the Research Explorer are retained by the authors and/or other copyright owners and it is a condition of accessing publications that users recognise and abide by the legal requirements associated with these rights.

\section{Takedown policy}

If you believe that this document breaches copyright please refer to the University of Manchester's Takedown Procedures [http://man.ac.uk/04Y6Bo] or contact uml.scholarlycommunications@manchester.ac.uk providing relevant details, so we can investigate your claim.

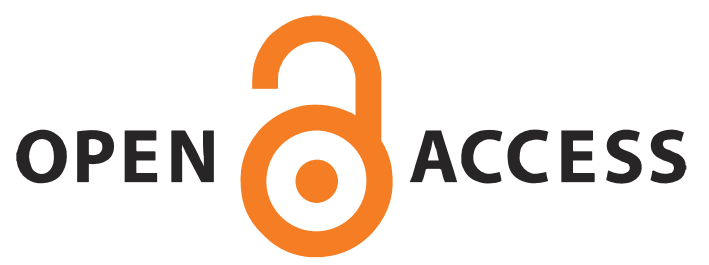




\title{
Truthmaking and Fundamentality
}

\author{
A.R.J. FISHER
}

\begin{abstract}
I apply the notion of truthmaking to the topic of fundamentality by articulating a truthmaker theory of fundamentality according to which some truths are truth-grounded in certain entities while the ones that don't stand in a metaphysicalsemantic relation to the truths that do. I motivate this view by critically discussing two problems with Ross Cameron's truthmaker theory of fundamentality. I then defend this view against Theodore Sider's objection that the truthmaking approach to fundamentality violates the purity constraint. Truthmaker theorists can have a troublefree theory of fundamentality.
\end{abstract}

\section{Introduction}

It is plausible to suppose that truth depends on reality in some way. Intuitively, whether or not the sentence 'Socrates is wise' is true is a matter of what is in the world and what it is like. Some metaphysicians think we can make sense of this intuition by invoking talk of truthmakers. Truthmakers are entities that make true certain truths. An orthodox account of truthmaking has developed around its most ardent defender, the late D. M. Armstrong, who claims that the existence of a truthmaker necessitates the truth of the proposition that it makes true. If entity $x$ is the truthmaker for $<\mathrm{p}>$ then it is impossible for $x$ to exist and $<\mathrm{p}>$ be false (Armstrong 1997, 115). ${ }^{1}$ Call this truthmaker-necessitarianism. Armstrong also believes that every truth must have a truthmaker: contingent truths, negative truths, generalisations and necessary truths all need truthmakers (Armstrong 2004, passim). Call this view truthmaker-maximalism. The conjunction of these views is orthodoxy in the metaphysics of truthmaking (Cameron 2008c, 107). But orthodoxy is occasionally controversial; many truthmaker theorists reject this account. ${ }^{2}$

Despite the internal disagreements, truthmaking is put to many uses in philosophy. It is used as a force to cleanse the arena of 'ontological cheats' such as Rylean behaviourism, Millian phenomenalism, instrumentalism and presentism. ${ }^{3}$ These theories, it is claimed, are to be rejected on the grounds that they violate the principle that truths must have an ontological ground. Presentism-the view that only the present exists-violates this principle since it allegedly admits truths about the past without truthmakers. Truthmaking is also put to more positive use as part of a theory of reference (Smith \& Brogaard 2000), a theory of knowledge by acquaintance (Mulligan 2006), and as an alternative criterion of ontological commitment to the Quinean view that ontology is exhausted by quantification (Cameron 2008b; Melia 2005). ${ }^{4}$ An underexplored application in the literature is putting truthmaking to use as a theory of fundamentality.

A theory of fundamentality broadly speaking is a theory about what is fundamental and how it is connected to what is nonfundamental. The phrase 'the fundamental' often refers to different things and the term 'fundamentality' gets used in different ways. Our understanding of these terms affects what kind of theory of fundamentality we hope to adopt. Jonathan Schaffer's (2009) use of the term 'fundamental' is solely about how a set of entities are structured according to instances of the relation of grounding. A theory of fundamentality, for Schaffer, is about entities grounding other entities. Theodore Sider's (2011) use of the term 'fundamental' is much less ontological than Schaffer's. Sider is mostly concerned with giving a theory of 
fundamentality that determines which truths are fundamental and how these truths are related to nonfundamental truths. So let us distinguish between, what I call, entityfundamentality and truth-fundamentality. Entity-fundamentality involves questions about whether an entity is fundamental or not, whereas truth-fundamentality is about which truths are fundamental and which ones are not. Schaffer's approach to the topic involves entity-fundamentality whereas Sider's is more about truth-fundamentality.

A truthmaker theory of fundamentality (broadly speaking) posits a relation of truthmaking in order to specify which truths are fundamental, how they are related to the world, and how they are related to nonfundamental truths. On the truthmaking approach, entity-fundamentality and truth-fundamentality are combined to give a theory about the world's structure in terms of a set of fundamental truthmakers and a fundamental description that is made up of a set of fundamental truths (although I am not suggesting there is a one-one correspondence between truthmaker and fundamental truth).

In what follows, I present Ross Cameron's (forthcoming) truthmaker theory of fundamentality (which analyses the truthmaking relation in terms of an 'in virtue of' relation between truths) and discuss two extant objections of his view ( $\$ 2$ ). This critique motivates me to articulate a distinct truthmaker theory of fundamentality that takes the truthmaking relation to be a grounding relation that holds strictly between entities of any ontological category and fundamental truths $(\mathbb{S} 3)$ and a semantic relation between fundamental and nonfundamental truths $(\$ 4)$. Along the way I show how my view does not succumb to the problems plagued by Cameron's and then reject an objection due to Sider (2011) that is directed at the truthmaking approach to fundamentality $(\$ 5)$. I conclude with a summary of the reasons to adopt my preferred truthmaker theory of fundamentality $(\mathbb{S} 6)$.

I do not motivate or defend the notion of truthmaking. I assume it is legitimate and ripe for application in the new topic of fundamentality. Hence I offer the conditional thesis: if you are a truthmaker theorist and acknowledge the need to provide a theory of fundamentality, you should accept my truthmaker theory of fundamentality. My starting point for assessing the truthmaking approach is Sider's critique of truthmaker theories of fundamentality. The hope is to construct a truthmaker theory of fundamentality that is free from Sider's objections. This paper therefore advances the debate between Sider and friends of truthmaking.

In brief, here is the view I defend. It has two main parts. First, the truthmaking relation is the relation of truthgrounding. An entity makes a truth true because it grounds the truth of the proposition in question. However, only a certain set of propositions are grounded in the existence of entities. These propositions are labelled as fundamental. Second, the truths that do not have truthmakers stand in an important semantic relation to the fundamental truths. These truths are called nonfundamental. My view draws inspiration from the following denial of maximalism, known as the moderate conception of truthmaking:

Truth Maker [maximalism] may be weakened so that only some truths, the primary ones, have truth makers, while other truths and falsehoods are derivable from the primary truths by means of truth-conditional semantics (Forrest \& Khlentzos 2000, 3, their italics; cf. Mellor 2009, 272).

On the moderate conception, it is not the case that every truth has a truthmaker in the sense that a truth stands in the truthmaking relation to some entity. Hence, this conception rejects maximalism; only primary or fundamental truths have truthmakers. But it does not follow that the truths that do not have truthmakers are left 
unaccounted for by reality. The proponent of the moderate conception thinks every truth that does not have a truthmaker is "derivable" from fundamental truths. The way in which we should understand the term "derivable" is to say that nonfundamental truths have some kind of semantics. I depart from the moderate conception of truthmaking by introducing a different kind of semantic relation between fundamental and nonfundamental truths. Following Sider, it is one of metaphysical semantics.

To be clear, there is no truthmaking relation between nonfundamental truths and entities. Indeed, there is no important and direct relation between the two. But this does not mean nonfundamental truths are unexplained or that there is no connection between nonfundamental truths and entities. Nonfundamental truths are accounted for in virtue of a metaphysical-semantic relation that holds between nonfundamental truths and the fundamental truths that directly have truthmakers. It is in this sense that they are accounted for by reality. My project can be seen as a sophisticated development of the moderate conception of truthmaking. Thus I call the view the moderate truthmaker theory of fundamentality (hereafter moderate truthmaker).

\section{Cameron's Truthmaker Theory of Fundamentality}

The aim of a theory of fundamentality in general is to provide an account of what is fundamental and how the fundamental is related to the nonfundamental (Sider 2011, 105). Two important concepts are involved in our notion of fundamentality: completeness and non-redundancy. To illustrate, suppose that God provides a complete account of the world by stating the truths of the world in some special book. On a loosely physicalist picture, it would be enough (it seems) for God to simply state truths about microphysical particles and how they are arranged in certain regions of spacetime to provide a complete account of the world. There is some sense in which talk about macrophysical objects follows from or is entailed by talk about microphysical objects (cf. Jackson 1998, 25). We would not expect God to include truths about macrophysical objects. But this does not mean that God has missed something. This book would still capture all the truths of the world since every truth is either fundamental or dependent upon some fundamental truth. This book is complete but contains no non-redundant truths. By specifying what is fundamental and how it is related to what is nonfundamental we can provide a theory that yields a complete and non-redundant description of reality. Therefore, a theory of fundamentality should give an account of:

a) what is fundamental

b) the relation between what is fundamental and the world

c) the relation between the fundamental and nonfundamental

An account of these three components comprises a theory of fundamentality or at least the barebones of a theory of fundamentality. Since the truthmaking approach involves a combination of entity-fundamentality and truth-fundamentality, a truthmaker theory of fundamentality fills in these components as follows:

1) what is fundamental is the set of truths made true by truthmakers

2) the relation between what is fundamental and the world is the truthmaking relation

3) the relation between fundamental and nonfundamental truths is some kind of 'in virtue of' relation

Note that 1) is more about which truths are fundamental and not about which entities are fundamental. In spelling out 2) we get a story about the truthmakers that 
make the fundamental truths true and so get a story about which entities are fundamental. After 3 ) is filled in we have an account of truth-fundamentality that best captures the notions of completeness that were highlighted in the metaphor of God writing the book of the world.

Cameron (forthcoming) has recently defended a particular type of truthmaker theory of fundamentality. On his view truths such as the proposition that $\mathrm{p}$ are true in virtue of other truths as follows:

$<\mathrm{p}>$ is true in virtue of $<\mathrm{q}>$

The 'is true in virtue of' expresses a primitive 'in virtue of' relation that has 'grounds' as its converse. So, if $<p>$ is true in virtue of $<q>$, then $<q>$ grounds $<p>$. This grounding relation is irreflexive, transitive and asymmetric such that no truth can ground itself, if $<\mathrm{q}>$ grounds $<\mathrm{p}>$ and $<\mathrm{r}>$ grounds $<\mathrm{q}>$, then $<\mathrm{r}>$ grounds $<\mathrm{p}>$, and if $<\mathrm{q}>$ grounds $<\mathrm{p}>$, then $<\mathrm{p}>$ cannot ground $<\mathrm{q}>$. This grounding relation has truths as its relata. It does not relate truths to entities. For Cameron, this 'in virtue of' relation is not the truthmaking relation. The truthmaking relation is analysed in terms of the 'in virtue of' relation as follows:

A proposition is made true by some things, the Xs, if and only if it is the brutely true pure existence claim that the Xs exist or it is true in virtue of the brutely true pure existence claim that the Xs exist (Cameron forthcoming, $\mathbb{2}$ ).

In other words, the Xs make $<\mathrm{p}>$ true iff either 1$)<\mathrm{p}>$ is not true in virtue of any other truth and $<$ p $>$ says the Xs exist (i.e., $<$ p $>=<$ the Xs exist $>$ ), or 2 ) $<$ p $>$ is true in virtue of $<$ the Xs exist $>$ and $<$ the Xs exist $>$ is brute. (A brute truth is a truth that is not true in virtue of any further truth.) The fundamental truths are then the truths that have truthmakers or stand in the truthmaking relation to some entity or entities because they are brute and solely about the existence of some entity or entities. The nonfundamental or derivative truths are the truths that are true in virtue of further truths. Thus, we have an account of our three components: i) the relation between what is fundamental and the world is the truthmaking relation that is analysed in terms of the 'in virtue of' relation which holds between truths, ii) what is fundamental is the set of truths that are not true in virtue of any further truths, and iii) the relation between fundamental and nonfundamental truths is the primitive 'in virtue of' relation.

One potentially attractive feature of Cameron's account is that the set of fundamental truths is merely a list of existential truths such as $<x$ exists $>,<y$ exists $>$, etc that are made true by such things as $x, y$, etc (Cameron 2008c, 112-3; forthcoming). To provide a fundamental description of reality God needs only the name of the entity (e.g., ' $x$ ') and the predicate 'exists' or the existential quantifier (' $\ldots \exists . . . ')$ and the identity predicate (e.g., 'there is an $x$ such that $x=a$ '). Therefore, the primitive ideology (i.e., the unanalysable set of terms) of Cameron's theory contains nothing more than the primitive apparatus of first-order predicate logic. There are no extra-logical (e.g., 'naturalness', 'resemblance') or quasi-logical (e.g., 'necessity', 'parthood') primitives (see Cameron forthcoming, $\$ 5$ ). The fact that Cameron's theory contains only logical primitives makes his view more ideologically parsimonious than theories that posit the set of logical primitives that most of us are ideologically committed to plus quasi-logical or extra-logical primitives. Since we should prefer, ceteris paribus, theories which are more ideologically parsimonious, we have a methodological reason to prefer his theory.

There are two objections to Cameron's theory that constitute a strong case against his truthmaker theory of fundamentality and provide motivation for the truthmaker 
theorist to look elsewhere. They are both due to Sider and concerned with the claim that only existential truths are fundamental.

The first objection is as follows. A theory of fundamentality contains a list of fundamental truths. The fundamental truths of a theory provide fundamental explanations of the world. These explanations are ultimate, complete and nonredundant descriptions of reality. So, fundamental explanations are meant to account for everything else in reality and must account for reality's complexity and structure. We can stipulate that satisfying explanations need to cite 'detailed general laws or patterns or mechanisms' (Sider 2011, 159). If the fundamental explanation is merely a list of existential truths (such as $<x$ exists $>,<y$ exists $>$, etc), we fail to provide a satisfying explanation because a list of existential truths does not cite laws, patterns or any kind of structure that one finds, say, in truths that involve monadic, dyadic or $n$ adic predicates (Sider 2011, 160). Since Cameron's view entails a fundamental explanation that contains merely existential truths, his view entails an unsatisfying fundamental explanation of reality. We should prefer theories of fundamentality that provide satisfying fundamental explanations of reality. Hence, we should reject Cameron's theory.

The second objection is less of a direct rejection and more about pointing out that Cameron's theory does not have a methodological advantage with respect to ideological parsimony. According to the second objection, Cameron's theory is not more ideologically parsimonious than its would-be rivals because its fundamental ideology, by his own lights, must contain non-logical primitives (Sider 2011, 157-8). The non-logical ideology of Cameron's theory is found by closely inspecting his ontology. Since Cameron accepts truthmaker-necessitarianism, contingent truths such as the truth that $a$ is $F$ require certain kinds of entities such as states of affairs or tropes whose existence necessitates the truth that $a$ is $F$. The particular $a$ on its own is not enough to necessitate the truth that $a$ is $F$ because there are worlds in which $a$ exists and $<\mathrm{a}$ is $\mathrm{F}>$ is false. Defenders of truthmaking, including Cameron, typically posit states of affairs (Armstrong 1997, 115-7; Cameron 2010). Since they posit states of affairs, they introduce certain types of names that commit them to a distinctive kind of ideology. If we posit states of affairs, we need the functor 'the state of affairs of $x$ ' to create a singular term that names a state of affairs such as 'the state of affairs of $a$ 's being F'. This functor is part of the fundamental ideology of Cameron's theory (Sider $2011,157)$. So, it is not the case that Cameron's ideology only contains logical primitives. Hence, his theory is not more ideologically parsimonious than its potential competitors. With respect to ideological parsimony, we have a draw on the scoresheet.

Both objections identify the limitations of attempting to restrict our theory of fundamentality to logical primitives. The lure of such a theory is its ideological parsimony. Nice work if you can get it; but we cannot since we are at pains to characterise our ontology and account for the patterns and laws of reality in ways that require non-logical primitives. On the view I articulate in the next two sections I avoid positing only fundamental existential truths. So my view does not claim to be more ideologically parsimonious than Cameron's view or other competitors. Also, I do not pretend to be ideologically committed to only logical primitives. The ontology that I posit requires non-logical primitives of some kind.

\section{Moderate Truthmaker I: Truthgrounding}

The truthmaking relation is a cross-categorial relation between entity and truth. I submit this relation is a relation of grounding. It has the important feature of being 
asymmetric, something that necessitation (Schaffer 2008, 11; 2010, 320) and supervenience (Armstrong 2004, 8) lack. Thus we should adopt the view that truthmaking is truthgrounding and deny that the truthmaking relation is the relation of necessitation or supervenience. Indeed, Gonzalo Rodriguez-Pereyra $(2005,18)$ states that truthmaking should be taken as an 'in virtue of' relation that holds between truth and entity. The 'in virtue of' relation as pointed out above has 'grounding' as its converse. So let us say truthmakers 'ground' the truth of the propositions they make true.

Our application of 'in virtue of' is different to Cameron's. In our case it is applied to an entity or entities and a truth whereas for Cameron it is applied merely to truths. More importantly, we are not using 'in virtue of' or grounding to analyse the truthmaking relation that holds between entity and truth. Rather we are identifying the truthmaking relation with the relation of truthgrounding. The grounding relation between entity and truth is primitive. So moderate truthmaker is distinct from Cameron's theory and should not be confused with it in any way. Let us now consider a particular version of truthmaking as truthgrounding to which I compare and develop the account of truthmaking endorsed by moderate truthmaker.

Schaffer has recently defended truthmaking as truthgrounding. According to his version of the view, 'the truthmaking relation is to be identified with certain instances of the dependence relation, namely, those which relate substance to truth' (Schaffer 2010, 310). There are two relevant features of his account. First, only substances can stand in the truthmaking relation to truths. Second, instances of grounding between substance and truth are no different in kind to other instances of grounding such as the mental being grounded in the physical or the fact that this ball is red and round is grounded in the fact that this ball is red and the fact that this ball is round.

The first feature of Schaffer's account is too strict to be built into the basic framework of our theory of truthmaking since it bans non-substance entities as candidates for truthmakers at the outset of inquiry. Such a restriction is prima facie implausible. Surely modes of substances, fundamental tropes and sparse immanent universals (if they exist) can be truthmakers for certain truths, especially when these entities play an important role in characterising reality. ${ }^{5}$ I submit as a methodological rule that we should be open to the possibility of the truthmaking relation holding between truths and whatever kinds of entities we posit in our fundamental ontology. To be clear, the current issue is about how we should understand ab initio the basic framework of our theory of truthmaking. As such we are yet to do any ontology with it. If a theory bans certain kinds of entities before we have done any ontology, we need a reason why we should accept such a restriction. There is no reason to accept the restriction that only substances stand in the truthmaking relation to truths. So we should reject the first feature of Schaffer's account of truthmaking.

Later on, I merely posit world-bound concrete individuals as sufficient truthmakers. Since concrete individuals can be regarded as substances, my ontology is compatible with Schaffer's restriction. Also, given that moderate truthmaker is a denial of truthmaker maximalism, only fundamental entities stand in the truthmaking relation to truths. So you might think there is no difference between my view and Schaffer's with respect to what kinds of entities stand in the truthmaking relation to truths. I reply that the restrictions are different in two ways. First, Schaffer restricts candidate truthmakers to just one kind of fundamental entity i.e., substances. I restrict candidate truthmakers to fundamental entities of any variety. I am open to the fact that we may need to posit fundamental entities of other varieties for independent 
reasons. If we need to posit sparse immanent universals (which count as fundamental in one sense), then I allow them to be truthmakers whereas Schaffer does not. Second, my restriction is not constitutive of our theory of truthmaking. It is a consequence of rejecting truthmaker maximalism plus an ontology of world-bound concrete individuals. Therefore, I do not by fiat restrict the work of truthmaking to worldbound concrete particulars; that is just what my ontology contains to serve as truthmakers. This latter fact is independent of our principle of truthmaking and a contingent fact as regards my attitudes to what our best ontology should contain. We should care about the latter difference between my view and Schaffer's because the basic framework of our theory of truthmaking is the foundation of our concept of truthmaking. It is one thing to impose a restriction by definition and quite another for it to fall out of independent commitments. In sum, the difference here between my view and Schaffer's is methodological: bracketing all other theses we should not restrict the truthmaking relation to substance and truth.

The second feature of Schaffer's account of truthmaking entails a commitment to a larger metaphysic of ground. I accept this feature but wish to clarify how the crosscategoriality of the truthmaking relation figures in a wider network of grounding relations. The grounding relation, for Schaffer and others, is of a strict partial order such that the relation is irreflexive, asymmetric and transitive. If truthmaking is an instance of the general grounding relation, it is irreflexive, asymmetric and transitive. However, if we accept that the truthmaking relation is strictly cross-categorial, there are no transitive cases of truthmaking. To see this, suppose entity $x$ makes $<\mathrm{p}>$ true. If so, to get a transitive case of truthmaking we need $<\mathrm{p}>$ to make some other truth, say, $<\mathrm{q}>$ true. But $<\mathrm{p}>$ cannot make $<\mathrm{q}>$ true due to the truthmaking relation being crosscategorial. The point here is not that the truthmaking relation fails to possess the logical property of being transitive. The point is that in reality there are no instances or cases of truthmaking that involve transitivity. We should accept this consequence in order to capture the fact that the concept of a truth having a truthmaker is strictly about an entity making a relevant truth true.

(I am happy with $x$ and $y$ collectively making $<\mathrm{p}>$ true, in which case $x$ is a partial ground for $<\mathrm{p}>$ 's truth. I am happy with the following too: if $x$ makes $<\mathrm{p}>$ true and $y$ makes $<\mathrm{q}>$ true, then $x, y$ make $<\mathrm{p} \& \mathrm{q}>$ true since the conjunctive truth stands directly in the truthmaking relation to $x, y$. I do not accept the claim that $<\mathrm{p}>$ and $<\mathrm{q}>$ both make true $<\mathrm{p} \& \mathrm{q}>$ since it would require the truthmaking relation holding between truths, which I reject. I say the same for cases of disjunction (if they are tenable). If $x$ makes $<\mathrm{p}>$ true or $x$ makes $<\mathrm{q}>$ true, then $x$ makes $<\mathrm{p} \mathrm{v} \mathrm{q}>$ true because the truthmaking relation holds between $x$ and $<\mathrm{p} \mathrm{v} \mathrm{q}>$.)

Truthgrounding relates entity to truth. It is a cross-categorial relation that is irreflexive, asymmetric and transitive (although there are no transitive cases of truthmaking). No entity can make itself true and in no way can an entity that makes a truth true have that truth make true that entity. I represent truthgrounding with the connective ' $\Leftarrow$ '. ' $x$ truth-grounds $<$ p $>$ ' means ' $x \Leftarrow \mathrm{p}$ '. I do not offer an analysis of grounding. But I do not regard this as a problem because many metaphysicians think the notion is respectable enough to be taken as primitive and put to work (see e.g., Rosen 2010). The 'grounding' connective can be interpreted in two ways. It can be interpreted as a dyadic predicate (i.e., '... grounds ...') or an operator (i.e., 'G(..., ...)'). On the latter interpretation, there are no relata strictly speaking and thus the connective does not commit us to facts, states of affairs or any other entities as relata of the relation. However, this interpretation entails that the relation can only relate 
propositions. Therefore, it is inappropriate to capture the fact that the truthmaking relation is cross-categorial (cf. Armstrong 2004, 5-6; Mellor 2009, 273). Assuming these are the only two interpretations available, I prefer the predicate interpretation. On this interpretation, we use singular or plural terms as arguments. Since the truthmaking relation is cross-categorial, we require a singular (or plural) term or singular (or plural) name of an entity on the left-hand side and the name of a truth or proposition on the right. On my view if $x$ makes $<\mathrm{p}>$ true then $x \Leftarrow<\mathrm{p}>$ (let us bracket plural cases). So:

(TM) For every fundamental truth $<\mathrm{p}>$, if $<\mathrm{p}>$ is true, there is an $x$ such that $x$ $\Leftarrow<\mathrm{p}>$.

There are certain principles of the general grounding relation that hold for truthmaking if it is a restricted instance of grounding. One principle is the following (see Correia 2011, 4):

(Nec) If $x$ grounds $y$, then $\square$ (if $x$ exists, then $y$ exists).

If truthmaking as truthgrounding is a restricted instance of the general grounding relation, but is also cross-categorial, then:

(Nec2) If $x \Leftarrow<\mathrm{p}>$, then $\square$ (if $x$ exists, $<\mathrm{p}>$ is true).

As such grounding is stronger than necessitation and we have rejected truthmakernecessitarianism insofar as it entails that the truthmaking relation is the relation of necessitation. Truthmakers do not necessitate truths; they ground truths. Necessitation is merely a requirement or feature of truthmaking. I am now going to argue that we need a principle like (Nec2) to find appropriate truthmakers for certain truths and to gain a genuine understanding of truthmaking as truthgrounding. My argument for this claim involves a demonstration of how I think we should find truthmakers for truths.

Let us assume that truthmaking is truthgrounding as per (TM). Let us also assume a version of physicalism such that all that exists is in space-time and supervenient on the physical. I am not endorsing physicalism. I am merely assuming it for the sake of illustration. In addition, this version of physicalism is not necessary for the explanation that follows. What I require is some version of the view where physical reality is crucial to how the world is structured. I also bracket issues about fitting in the existence of abstracta into this version of physicalism. It is not relevant here.

Given physicalism, in our world there is a micro-physical base to reality which is thus-and-so. This micro-physical base is made up of multiple fundamental entities being a certain way. Call this 'the fundamental base' of our world. In our world the fundamental base is unique in the following sense: it existing as it is in our world entails that it cannot exist as it is in any other world. To illustrate, suppose the fundamental base of our world, now call it $f 1$, is part of the fundamental base, call it $f 2$, of an expanded world. This expanded world cannot have $f 1$ as it is in our world; it can only have $f 1$ as a part of its unique fundamental base (even though $f 1$ in the expanded world is an intrinsic duplicate of $f 1$ in our world). The number of fundamental entities that constitute $f 1$ of our world is 'locked in' at that number. We cannot add another fundamental entity to $f 1$ and still have $f 1$ as a unique fundamental base of our world. As a result, we need an essentialist treatment of the fundamental base of a given world (more on this below). Let us further suppose the fundamental base of our world fixes the rest of reality. Once we have the fundamental base we have the rest of the physical objects that exist in our world such as the red rose. We could have had the red rose in virtue of some other fundamental base. But let us put that point to one side. Instead, consider the truth that the rose is red and suppose it stands in the truthmaking relation to some entity or entities. If so, this truth is grounded in 
the red rose because our world has a unique fundamental base that cannot exist as it is in any other world. Given that $f 1$ fixes the red rose existing as it is, it is impossible for the red rose to exist as it is and <the rose is red $>$ be false. So the red rose grounds the truth of $<$ the rose is red $>$. This explanation appeals to the impossibility of our world being a certain way and the given truth being true. This impossibility requirement is nothing more than necessitation between entity and truth. Therefore, we need truthgrounding to have necessitation as a feature. It allows us to explain how the grounding relation holds between an entity and a truth and therefore enables us to grasp the notion of truthmaking as truthgrounding. In other words, we should accept (Nec2).

Accepting a principle like $(\mathrm{Nec} 2)$ can help us determine when a certain truth is made true by a truthmaker. In the case of $<$ the rose is red $>$ we found the red rose existing as it is to be a sufficient truthmaker. We can say the same thing about negative (and hence general) truths if these truths stand in the truthmaking relation to some entity or entities. Consider the truth that there are no bunyips. (Bunyips are mythical creatures that allegedly lurk in the billabongs and creeks of Australia.) We can speculate that because the fundamental base of our world exists as it is and cannot exist as it is in any other world it is a sufficient truthmaker for <there are no bunyips>. Schaffer provides this type of proposal as follows:

$\ldots$ any difference in the truth of $<$ there are no dragons $>$ must stem from some difference in what is fundamental. If there can only be one fundament, and it is the world, then any difference in the truth of <there are no dragons $>$ can only possibly stem from a difference in the world. Fixing the fundament as actuality fixes the world, and in so doing fixes the truth of <there are no dragons> (Schaffer 2010, 321-2); (cf. Cheyne \& Pigden 2006, 257-8).

Schaffer's explanation employs the doctrine of priority monism: there is only one fundamental entity and it is the world. Elsewhere (Fisher 2014), I have argued that the defender of pluralism - the view that there are multiple fundamental entities - can adopt this explanation so long as they say the unique fundament of our world existing as it is cannot be the same fundament in another world (which is what I alluded to above). In short, if the pluralist 'locks in' the number of their fundamental entities in the same way that the monist does, we arrive at the same result. For, as Schaffer says, 'the solution under consideration requires that there is some fixed finite number of truthmakers. The number need not be one' (2010, 322, his italics).

To recap: if we have an expanded world that has the fundament or fundamental base of our world as a part with an additional bunyip or dragon part, then we do not have our fundament as a fundament. It is rather part of some other fundament. So it is impossible for our fundament to exist and the truth that there are no dragons or bunyips be false. But this explanation is a condition of necessitation. Therefore, truthmaking as truthgrounding requires necessitation as a feature of the truthmaking relation. In other words, we should accept (Nec2). To reiterate, this is a good thing. (Nec2) ensures we grasp the concept of truthmaking as truthgrounding and find truthmakers for contingent predicational truths and negative truths (and hence general truths) in an appropriate manner. We do not appeal to spooky entities such as totality states of affairs or negative facts.

However, we take on two essentialist commitments: 1) we commit ourselves to the fundament of every world existing as it is, and 2) we commit ourselves to concrete individuals existing as they do in the worlds in which they exist. The first commitment, to be clear, is not a form of hyper-essentialism according to which fundamental entities must exist as they exactly are even in extrinsic respects. What I am essentialist about is 
the fundament of a given world, not the individual entities that constitute the fundament. The fundament $f 1$ of world 1 can exist in world 2 as an intrinsic duplicate but $f 1$ would not be its fundament. Each fundament of every world is what it is essentially. It could not be any other way qua fundament. I cannot properly defend this commitment here because it would take us too far afield into the topic of essences and essentialism. I simply acknowledge that the first commitment is a cost. The second commitment entails that truthmakers are 'essentialised' or world-bound. I also acknowledge this is a cost but I think this commitment is inevitable because the concept of truthmaking implies the idea of something being necessarily sufficient for the truth of a given proposition. If we accept truthmaking, we must accept as truthmakers entities that are essentialised in some way, whether they are tropes (such as my cup's whiteness which cannot be had by any other object), states of affairs (such as my cup's being white which has the universal component of being white and the particular component of my cup essentially) or world-bound concrete individuals (such as the white cup of this world which cannot be any other colour besides white). I prefer to believe in world-bound concrete individuals insofar as they suffice to account for all the fundamental truths that need truthmakers. If talk of 'entities existing as they are' is legitimate, then they do (I won't defend this point here). Hence, I posit an ontology of concrete individuals such as the white cup, the charged electron, etc. They are thick particulars in a certain sense (cf. Melia 2005 and his sensible nominalism). And for this reason our fundamental ideology contains non-logical predicates such as '... is white', '... is charged', etc.

Thus far I have provided an account of the relation between truths and reality. These are the truths that are made true by entities and thus stand in the truthmaking relation to the world. Moderate truthmaker does not entail that all truths stand in the truthmaking relation to reality. Some truths are semantically related to the truths which are made true by truthmakers. I discuss this semantic relation in the next section.

\section{Moderate Truthmaker II: Metaphysical Semantics}

Moderate truthmaker provides an account of how fundamental truths are related to nonfundamental truths. The connection between fundamental and nonfundamental truths is one of semantics. Forrest and Khlentzos tell us that,

... God knows only the primary truths and that the truths derivable from these by semantics are human truths. Extraterrestrials, nay postmodernists, could then have a different semantics from ordinary human beings and provided it was grounded on the same primary truths it would be as true but not necessarily as good as ours $(2000,6)$.

Their suggestion is that primary truths are expressed in a fundamental language or a language that is more fundamental than human and alien languages. The fundamental language is the language that God speaks and the truths of the fundamental language are 'better' at describing the world than the truths of ordinary language. It seems there is an important distinction between fundamental and nonfundamental languages that ought to be recognised here. The distinction is not foreign to metaphysics. Sider's (2011) metaphysics is based on the distinction and Cameron (2008b) argues that the distinction can get us out of certain problems in the philosophy of mathematics and the composition of material objects (for discussion see Korman 2013).

The distinction in one form or another comes about quite naturally when thinking about problems in ontology. Once we realise ordinary language does not provide a 
perfect description of the world or contains statements that are true without being ontologically committed to what they quantify over there is a sense in which ordinary language is one thing and the language of ontology another. Admittedly, there are many ways to understand the distinction and whether it should lead to drawing a divide between languages. I won't discuss these issues here. I assume there is a distinction worth drawing and one that is implied by the suggestion that God only knows the fundamental truths which are the semantic grounds for truths in English and other nonfundamental languages. I acknowledge the distinction is a cost.

What exactly is the semantic relation that is said to hold between fundamental and nonfundamental truths? Forrest and Khlentzos claim that '[nonprimary] truths depend on the primary ones in ways systematised by truth-conditional semantics' $(2000,10)$. According to truth-conditional semantics traditionally understood, the goal is to provide theorems that state the truth-conditions for every sentence in some language. The hope is to provide a theory of meaning by providing meanings that are stated in languages by users who use their language as a meta-language. A well-known approach is found in the work of Donald Davidson (1984). On the Davidsonian approach the statements of truth-conditions for certain sentences are instances of the T-schema:

Sentence $S$ of $\mathrm{L}$ is true in $\mathrm{L}$ iff $\mathrm{S}$.

But for moderate truthmaker this approach is insufficient. If we wish to explain how nonfundamental truths of a nonfundamental language have a semantics in terms of fundamental truths, we need to state the truth-conditions of nonfundamental sentences as fundamental truth-conditions. So we need a semantic theory that accounts for the meanings of these sentences in purely fundamental terms. Fortunately, Sider provides an alternative semantic theory that fills this requirement, a semantic theory that moderate truthmaker can incorporate into their theory of fundamentality. I suggest we drop talk of 'truth-conditional' or 'linguistic' semantics and adopt what Sider (2011) calls 'metaphysical' semantics. He writes,

A metaphysical semantics is a semantic theory [where] ... meanings are to be given in purely joint-carving terms. For example, if the semantic theory takes the form of a truth-theory, then the truth-conditions must be stated in perfectly joint-carving terms (Sider 2011, 112).

Sider's statement of the theory involves the notion of predicates, operators and other devices of expression 'carving at the joints'. Moderate truthmaker does not traffic in such ideology. So, we need to implement a metaphysical-semantic theory that does not appeal to talk of 'joint-carving'. For moderate truthmaker, the truthconditions of sentences of nonfundamental languages are stated purely in terms of fundamental truths of the fundamental language. The fundamental truths are simply the truths made true by reality. We can then put forth a metaphysical semantics for some language $\mathrm{L}$ (in the form of a truth theory) that has theorems as follows:

Sentence $\mathrm{S}$ of $\mathrm{L}$ is true in $\mathrm{L}$ if and only if $\varphi$ (Sider 2011, 113).

In order to give the meaning of $S$ in terms of fundamental truths we need $\varphi$ to express a fundamental truth or some set of fundamental truths and we need the notion of metaphysical semantics to allow us to say nonfundamental truths such as $S$ have a metaphysical semantics. The constraint on a metaphysical semantics that gets us to the fundamental notions of a fundamental language is whether a truth has a truthmaker or not. The fundamental truths of the fundamental language are the truths that have truthmakers. 
It will be instructive to address one objection at this point. The notion of metaphysical semantics is meant to provide truth-conditions of the form ' $\mathrm{S}$ of $\mathrm{L}$ is true in $L$ if and only if $\varphi$ ' such that ' $\varphi$ ' only contains fundamental notions. You may object that metaphysical semantics cannot be incorporated into a Tarskian truth theory because the homophonic nature of instances of the T-schema is required to capture compositionality in truth-theoretic terms. In other words, a Tarskian truth theory defines truth-conditions for statements in recursive terms and thus explains how the truth-values of complex statements depend (in some sense) on the truth-values of simpler statements. But a metaphysical semantics has non-homophonic truthconditions because the logical complexity of, say, ' $\varphi$ ' and sentence $S$ of language $L$ are completely different. So, we cannot provide a plausible recursive conception of truthconditions on this basis.

I reply that this objection misunderstands the project of metaphysical semantics. The appeal to a truth theory under the guise of the Davidsonian approach is merely for the sake of illustration. As Sider admits, 'the metaphysical semanticist could abandon the Davidsonian approach. I have chosen that approach largely because it's simple, not because metaphysical semantics is wedded to it' (Sider 2011, 115). So, we should not think of metaphysical semantics as providing the meaning of more complex statements using standard notions of compositionality. Metaphysical semantics can incorporate a Tarksian truth theory but it will amount to an unorthodox application. Furthermore, metaphysical semantics is not merely about assigning truth-conditions for certain sentences. As Sider claims, a metaphysical semantics for a sentence can take on the form of 'either a truth-condition, an expression-condition, a proof-condition, or perhaps some other sort of semantic condition, that is assigned to that sentence by some metaphysical semantics for its language' $(2011,116)$.

You may object that there is no difference between moderate truthmaker and Sider's theory. Such an objection misunderstands how I am using Sider's notion of metaphysical semantics as part of moderate truthmaker. It is true that, as regards the connection between fundamental and nonfundamental truths, my theory and Sider's are more or less equivalent. But the difference between the two theories turns on how we understand the connection between fundamental truth and reality. According to moderate truthmaker, fundamental truths are made true by reality. This is the connection between fundamental truth and reality for moderate truthmaker; it is understood in terms of the notion of truthmaking. For Sider, the connection between truth and reality is understood in terms of the notion of 'structure' or 'joint-carving' that applies at the sub-propositional level or at the level of a proposition's constituents (Sider 2011, $\$ 6.3$ ). A term such as a predicate (say '... is F') or an operator (say 'necessarily, ...') connects to fundamental reality just in case the term is structural or 'carves at the joints'. A sentence that contains only structural terms is a sentence that carves reality at the joints. (More should be said here, but this paper is not a direct assessment of Sider's full view.) At the same time, moderate truthmaker is not to be thought of as an extension of Sider's theory with the addition of truthmaking. The notion of metaphysical semantics as invoked by moderate truthmaker does not appeal to talk of joint-carving. And the notion of metaphysical semantics does not entail the concept of joint-carving. The notion of truthmaking replaces the notion of jointcarving. Truthmaking and whether a truth stands in the truthgrounding relation to a fundamental entity is the key constraint on a metaphysical semantics. The conjunction of a primitive truthgrounding predicate and the notion of metaphysical semantics 
(without talk of joint-carving) renders moderate truthmaker distinct from Sider's theory.

Admittedly, we have before us a sketch of a semantic theory. But the point of this discussion is to show how the relation between nonfundamental and fundamental truths can be understood within a truthmaker theory of fundamentality and that Sider's metaphysical semantics can be consistently adopted by moderate truthmaker. Although the semantic theory is somewhat programmatic, I do not think this is a tremendous drawback because opponents of the truthmaking approach to fundamentality, such as Sider, provide just as little details as I have outlined here. Sider admits that:

What I have said about metaphysical semantics falls far short of a full characterization, and it could surely be improved in various ways. However, it is unlikely that there is any single best way to improve it. The notion of a metaphysical semantics for a language, after all, is a high-level notion-a notion posited in the course of explaining a high-level phenomenon, the phenomenon of language-use by flesh and blood people, as well as equally good ways to carve the world into groups of phenomena to be explained. ... We should take a nonfundamental, no doubt vague, and perhaps not even uniquely correct, approach to the question of the relationship between fundamental and nonfundamental $(2011,115)$.

So I do not think it is a devastating objection to say that moderate truthmaker is incomplete or lacks sufficient detail to be an attractive theory of fundamentality because the appeal to metaphysical semantics is programmatic or sketchy. It is on a par with its main competition.

Let us summarise moderate truthmaker. Fundamental truths are made true by truthmakers. The truthmaking relation holds between fundamental truths and whatever our truthmakers turn out to be. I speculate that concrete individuals are sufficient truthmakers, but if for reasons independent of the principle of truthmaking, universals, states of affairs or sets are posited, they too can serve as truthmakers. But they would, like concrete individuals, only serve as truthmakers for truths of the fundamental language.

More importantly, the truths of the fundamental language are of many varieties. Moderate truthmaker accepts predicational, relational, general and quantificational truths (e.g., 'a is F', 'a bears R to b', 'something is F') as fundamental. Such truths allow us to explain the complexity of the world that we think needs to be accounted for in a fundamental explanation. These truths need to have this structure to explain patterns and mechanisms that are found in nature. If the fundamental truths consisted merely of existential truths, we would fail to provide satisfying fundamental explanations of patterns, laws and mechanisms that ought to be explained by the fundamental truths of our theory. As noted above, Sider mounts this objection against Cameron's truthmaker theory of fundamentality. My view is not subject to this objection since I do not merely posit existential truths.

Furthermore, I do not claim that my fundamental ideology consists solely of logical primitives. Hence, I do not smuggle in any fundamental ideology that was not declared at the outset (smuggling in undeclared ideology is a defect of Cameron's view). Lastly, the relation between truths of the fundamental language and truths of nonfundamental languages is one of semantics. Truths of nonfundamental languages have a metaphysical semantics, which is to say, the meaning of nonfundamental truths is given in terms of fundamental truths.

Sider has recently argued that all truthmaker theories of fundamentality should be rejected because they violate the purity constraint. If this objection is sound, we should 
reject the truthmaking approach to fundamentality. In the next section, I consider Sider's objection and argue that moderate truthmaker can provide an adequate reply. Thus, the view remains intact and for this reason if we are truthmaker theorists we should accept moderate truthmaker as our best truthmaker theory of fundamentality.

\section{The Objection from Purity}

The concept of fundamentality involves the notion of 'purity'. The notion of 'purity' is derived from the idea that fundamental descriptions involve nothing more than fundamental truths. Intuitively, all God has to do to provide a complete account of reality is to provide the fundamental description of reality. The fundamental description won't mention (or use) any nonfundamental terms or refer to any nonfundamental entities, etc. In other words, 'fundamental truths involve only fundamental notions' (Sider 2011, 106, his italics). Call this the purity constraint, or purity for short. Purity as stated consists of two main concepts: the notion of a fundamental truth and the notion of a fundamental notion. Insofar as these concepts are yet to be underpinned by richer notions of a particular theory the purity constraint is merely in its skeletal form. Purity as stated does not entail a commitment to a specific metaphysical framework that explains the notion of a fundamental truth and the notion of a fundamental notion.

Before we see how Sider construes purity in his particular framework we should understand how purity is supposed to work. To take Sider's example, consider the truth 'there exists a city'. According to purity, this truth is not fundamental since 'city' is nonfundamental. Now consider 'there is a city in virtue of $x$ '. This is a nonfundamental truth since it also involves the notion of 'city'. If we include a fundamental operator, say, 'necessarily, ...' or ' $\square$ ' in our theory, then truths that involve ' $\square$ ' and nonfundamental notions such as 'city' will also turn out nonfundamental (e.g., ' $\square$ all Cs are cities' is nonfundamental). But if ' $\square$ ' is involved in a truth that has only fundamental notions, then the corresponding truth is fundamental. For instance, ' $\square$ all Cs are Cs' is fundamental (Sider 2011, 108). So, purity tells us that so long as a truth involves only fundamental notions it will be fundamental. If a purported fundamental truth involves a nonfundamental notion, then given the purity constraint, it is not fundamental. In this sense purity has a normative element. It prescribes that fundamental truths must involve fundamental notions (the sense of 'must' here is normative in addition to being of necessity). Purity is supposed to be a sweeping constraint: 'it requires facts about the relationship between the fundamental and the nonfundamental to be themselves nonfundamental' (Sider 2011, 107, his italics).

Let us look at Sider's construal of purity using his own theory. Sider's explanation of the concepts of a fundamental truth and fundamental notion appeals to talk of a fundamental language and the notion of structure. For Sider, a notion is fundamental just in case the notion (or associated term) is part of the fundamental language. The notion of 'fundamental truth' is understood as a truth that is expressed in or is part of the fundamental language. The concept of something 'being fundamental' is equivalent to the notion of structure, which Sider expresses using an operator (he calls ' $\mathrm{S}$ ') that attaches to terms of any grammatical category (see Sider 2011, $\$ 6.3$ ). Therefore, according to Sider, to say that term $t$ is structural is to say that $t$ is fundamental. And for $t$ to be fundamental it must be part of the fundamental language because in the fundamental language all (and only) primitive expressions perfectly carve at the joints 
(see Sider 2011, 92, n. 14). Fundamental notions are nothing more than primitive notions that are part of the fundamental language or stated in fundamental terms.

You may object that purity on this understanding entails that truths that are part of the fundamental language involve notions that are part of the fundamental language. Therefore, this characterisation of purity renders purity nothing more than a logical truth and as a result says nothing. Indeed, the objection continues, it is more appropriate to understand purity in terms of metaphysical semantics, especially since Sider and I both accept this notion. So, purity should be: every truth without a metaphysical semantics contains only fundamental notions. In other words, $x$ is a fundamental truth just in case $x$ does not have a metaphysical semantics, and so all connecting truths must have a metaphysical semantics.

However, purity is not a logical truth. Purity is a constraint and as such it tells us that, on my understanding, truths that are said to be part of the fundamental language must involve notions that are part of the fundamental language. There is nothing in my understanding of purity that renders it a tautology. Purity is not descriptive, it is prescriptive. And its application is certainly non-trivial. Furthermore, I object that the opposing understanding of purity in terms of metaphysical semantics is plausible because its definition of purity and 'fundamental truth' appeals to a nonfundamental notion. If we say that a fundamental notion is one that lacks a metaphysical semantics, we appeal to the nonfundamental notion of metaphysical semantics to define purity. And if we understand 'fundamental truth' and 'fundamental notion' and 'the fundamental' more generally in terms of not having a metaphysical semantics, we say nothing about how fundamental truths connect to reality and its structure. All we have said is that there is a certain set of truths that lack a certain semantic property. What is required of a theory of fundamentality is that whatever is fundamental is accounted for in terms of a fundamental relation between fundamental truths/notions and reality. This is the main reason why Sider posits the notion of structure and introduces talk of 'joint-carving' into his fundamental ideology. Sider thinks that an expression or term that does not carve at the joints has a metaphysical semantics (see Sider 2011, 116). The fundamental notion of joint-carving is used to demarcate which expressions have a particular semantic property and not vice-versa. Therefore, it is wrong-headed to say that an expression carves at the joints (i.e., is fundamental) because it lacks a metaphysical semantics.

Sider's interpretation of purity, it seems, comes fully loaded with his notion of structure and talk of 'joint-carving'. A truthmaker theorist could simply reject purity on the grounds that they do not sign up to Sider's understanding of what it is for something to be fundamental. A truthmaker theorist could say that what is nonfundamental is determined by whether something depends on something else such that 'the fundamental' is understood as that which is independent or ungrounded. This would render the idea of a 'fundamental truth' unintelligible since all truths, for truthmaker theorists, depend on the entities that make them true. If there are no fundamental truths, purity has no force because it is a test for fundamental truths. This is one possible response that the truthmaker theorist might be able to use when responding to Sider's objection from purity. There are places where Sider recognises this move as a legitimate response on behalf of the truthmaker theorist. He writes, '... one could ... construe the [truthmaker] theory [of fundamentality] as rejecting the idea of a fundamental fact altogether, holding simply that the fundamental consists solely of entities' $(2011,157)$. But this response is not in the spirit of moderate truthmaker, nor is it dialectically satisfying. A more promising reply would be to demonstrate how 
a truthmaker theory meets purity using its own framework as opposed to rejecting purity outright.

The truthmaker theorist can construe purity without accepting Sider's notion of joint-carving. All we need in order to accept purity is the idea that fundamental notions are expressed by terms that are part of the fundamental language, and that a fundamental truth is similarly expressed in the fundamental language. We then give a truthmaker-friendly explanation of fundamental truth and fundamental notion. For moderate truthmaker, the truth that $\mathrm{a}$ is $\mathrm{F}$ is part of the fundamental language because it is truth-grounded in some entity or entities. Fundamental notions are, then, the notions that are expressed by the truths that are truth-grounded in some entity or entities. The sentence ' $a$ is F' expresses the truth that a is F and this sentence contains the predicate '... is F' which expresses the notion $F$. It is in virtue of that predicate being part of a sentence that expresses this truth that the notion of ' $\mathrm{F}$ ' is fundamental. If moderate truthmaker can adopt purity using their own framework, we have an important dialectical result. We have two differing construals of purity that are mutually intelligible because they are intertranslatable into each other's metaphysical tool-kit. The remaining challenge is whether or not moderate truthmaker violates purity.

Let us present Sider's objection from purity against the truthmaking approach to fundamentality. First, consider the truth:

(A1) 'there exists a city' have:

Let us suppose this truth is made true by some plurality of truthmakers. So we

(A2) 'there exists a city' is made true by some plurality of truthmakers'

This latter truth is a connecting truth. It is telling us about how (A1) is connected to its truthmakers. If (A2) is taken as fundamental, we violate purity. Sider continues, Now, given purity, claims like these [i.e., (A2)] cannot express fundamental facts.

(Otherwise, telling the fundamental story of the world would require bringing in the notion of a city.) But truthmaker theorists regularly make claims like these without giving any hint of how they might be reductively explained $(2011,161)$.

If we violate purity, we should reject the truthmaking approach to fundamentality. Sider thinks we have violated purity. So, we should reject the truthmaking approach to fundamentality. We can reply to Sider's objection as follows. Truthmaker theorists do provide hints about how they reductively explain truths such as (A2). We saw some of these hints in the moderate conception of truthmaking and I developed them in detail when I articulated moderate truthmaker. Only a naïve view would say (A2) is fundamental. According to moderate truthmaker, (A2) is not a fundamental truth. It involves a truth (namely, (A1)) that does not have a truthmaker. Hence (A2) is not part of the fundamental language and not part of the fundamental story of the world. Nonfundamental truths do not have truthmakers according to moderate truthmaker. Nonfundamental truths have a metaphysical semantics. This is a similar move to Sider's conception of completeness where every expression that involves non-jointcarving notions requires a metaphysical semantics (Sider 2011, 116). The notion of a metaphysical semantics is not fundamental and so cannot violate purity. Although the notion of metaphysical semantics is undefined, it is not part of the fundamental language and so not a primitive notion in this sense. If Sider mounts the objection against moderate truthmaker with examples that involve notions such as 'city', etc, the objection from purity misses its target. 
You might think the objection from purity should be directly applied to the truths that have truthmakers. Isn't it the facts about truthmaking, that is, facts about truthmakers making truths true that the test of purity should be applied to? Ok. So let us consider the truth:

(A3) ' $x$ makes true sentence ' $S$ '

Now, (A3) is a connecting truth for it connects a truthmaker (an element of ontology) to a truth. Supposing that (A3) is a fundamental connecting truth, does it involve a nonfundamental notion that would lead to a violation of purity? I say no, since, according to moderate truthmaker, the notion of a truthmaker, the notion of a fundamental truth, ${ }^{6}$ and the notion of 'makes true' are all fundamental in the sense that they are all part of the fundamental language. Therefore, purity is not violated. (A3) is a fundamental connecting truth. Facts about truthmaking are fundamental in this sense of 'fundamental'. To be clear, moderate truthmaker is ideologically committed to a truthgrounding predicate. The relevant primitive is '.. truth-grounds

' which relates an entity or entities on the left-hand side to a truth on the right. On Sider's construal, the 'makes-true' predicate is a joint-carving term, just like other devices of expression. If an operator is taken as fundamental and it operates on fundamental sentences, then the resulting sentence is fundamental. Consider:

(A4) ' $\square$ (all sounds have timbre)'

If the notion of 'sound' and 'timbre' are fundamental, and ' $\square$ ' is fundamental in the sense that it is primitive or unanalysable in the theory, then (A4) is pure. (A3) is analogous to (A4), and just as pure. The point of positing a primitive like 'makes true' is to claim that connecting truths are fundamental. For the posited notion is taken as a primitive of the fundamental language. But, it is not the case that all connecting truths are nonfundamental (on pain of violating purity) since some connecting truths such as ' $x$ makes true $<\mathrm{p}>$ ' are stated entirely in the fundamental language and hence involve only fundamental notions. Purity only implies that connecting truths that involve nonfundamental notions must be nonfundamental. If a connecting truth has only fundamental notions, it is fundamental.

You might object as follows. Take the name ' $x$ ' and suppose it refers to $x$ and then suppose that $<\mathrm{p}>$ is made true by $x$. It follows that $x$ makes true $<\mathrm{p}>$. But if $x$ makes true $<\mathrm{p}>$, then 'makes true' relates something that is fundamental, i.e., $x$, to something that is nonfundamental, namely, $<\mathrm{p}>$. Therefore, moderate truthmaker cannot say the fact that $x$ makes $<\mathrm{p}>$ true is fundamental.

I reply that the sense of the term 'fundamental' has shifted. This objection assumes that what makes something fundamental is determined by whether something depends on something else. In particular, this objection assumes that having a truthmaker is sufficient for not being a fundamental fact, i.e., $<\mathrm{p}>$ is not fundamental because it holds in virtue of $x$. We have switched from truth-fundamentality to entityfundamentality. But there are two reasons to reject this assumption. First, this criterion would beg the question against Sider and hence be useless in our current dispute. Second, it is unfair to shift the sense of the term 'fundamental' to reject moderate truthmaker. The sense of the term 'fundamental' I have been working with, and the sense that Sider uses, maintains that something is fundamental just when it is a term that is part of the fundamental language or a truth that is expressed in the fundamental language. If anything I am committed to the opposite: having a truthmaker is sufficient for being a fundamental fact. You may think this is odd and not part of your typical theory of truthmaking. You may be right. Moderate truthmaker is unorthodox. But I motivated it by drawing on insights from the 
moderate conception of truthmaking which claims that only a certain set of truths have truthmakers.

There is an answer to the distinct question: what are the truthmakers for facts about truthmaking? I do not have space for a full discussion of this issue, but one answer is: $x$ is the truthmaker for $<x$ makes true $<\mathrm{p}>>$. This answer is defended by Karen Bennett (2011), but found in (David 2005, 144, n.3) and (Cameron 2008a, 270 ). Another answer involves the semantic values of the truth (i.e., $<p>$ ) that is made true such that the truthmaker for $<x$ makes true $<\mathrm{p}>>$ is the sum of $x$ and whatever makes it true that ' $p$ ' has a semantic value whereby it applies to $x$. Both answers require further discussion, but this issue is outside the scope of this paper. I am operating within the boundaries marked out by purity.

In sum, moderate truthmaker accepts that facts about truthmaking are fundamental. These connecting facts pass the test of purity. Given moderate truthmaker, these notions are all part of the fundamental language. Furthermore, nonfundamental truths that are expressed in nonfundamental languages do not have truthmakers. These truths have a metaphysical semantics, i.e., they have metaphysical truth-conditions that are specified using fundamental truths (if the semantics takes on the form of a truth theory). Facts about the connection between fundamental and nonfundamental truths are not fundamental; they are not part of the fundamental language and they are not part of the story that God has to tell in order to provide a complete account of reality. So, the truthmaker theorist can reject Sider's objection from purity on non-question-begging terms.

\section{Conclusion}

I am attracted to the notion of truthmaking. Intuitively, truths are true because of what things there are in the world and what they are like individually and collectively. I did not defend the notion of truthmaking, although I admit truthmaker theorists need to say more about why we should adopt the concept and incorporate it into our metaphysics. Assuming the notion is legitimate I think we can build a trouble-free truthmaker theory of fundamentality. The view that I defended - moderate truthmaker - entails that a special class of truths are truth-grounded in certain entities while the truths that are not truth-grounded are connected to the truths that do in virtue of a metaphysical semantics. This view also has many theoretical benefits that count as reasons to prefer it over other theories of fundamentality.

First, as argued above, if we are truthmaker theorists and wish to give a theory of fundamentality, the best account we can give is moderate truthmaker. It has a robust grounding relation between entities and fundamental truths and a flexible semantic apparatus that connects fundamental truths to nonfundamental truths of differing languages. It is not plagued by problems of explaining the patterns and structure of the world that we think a fundamental description should provide since its primitive ideology contains non-logical predicates, quantifiers and other devices of expression.

Second, moderate truthmaker rejects maximalism. Some truths, indeed most truths, receive a metaphysical semantics. So, we are not pestered by a quest to find truthmakers for every truth and possibly posit unpalatable beings. However, the fact that most truths do not have truthmakers does not entail that these truths are unaccounted for because they do not directly stand in the truthmaking relation to entities in our ontology. On the contrary, it is because these truths stand in the metaphysical-semantic relation to fundamental truths that we can say they are explained or accounted for. The fundamental truths, then, stand in the truthmaking 
relation to the elements of our ontology which serve ultimately as the basis for all explanation. If there are fundamental negative truths, the fundamental base of our world existing as it is makes true such truths.

Third, we can draw a quick comparison with Sider's theory of fundamentality that results in a final reason to adopt moderate truthmaker. The difference-maker, roughly speaking, between Sider's view and moderate truthmaker is the notion of structure or joint-carving versus truthmaking. I think that if you have a better grip on the notion of truthmaking and find the notion of structure mysterious, then, assuming we need to endorse some theory of fundamentality, you should find moderate truthmaker a more promising option.

I now end on a further development of moderate truthmaker that has to be properly addressed elsewhere. According to moderate truthmaker, the 'makes-true' predicate expresses a fundamental notion in the fundamental language. The fundamental description of reality will therefore contain sentences involving what makes true what. When it comes to God creating reality he will in one fell swoop endow the world with a physical structure standing in the truthmaking relation to a certain class of truths. On this view, it is not enough for God to just create truthmakers. God has to say what makes true what and this will require creating at the same time truths that have truthmakers. Whether or not this is an odd consequence will depend on what you take the primary bearers of truth to be and what you think their nature consists in. So our theory of truthmaking needs a fleshed-out account of truth-bearers to be fully complete. I leave this concern for another paper. ${ }^{7}$

School of Social Sciences University of Manchester

\section{Notes}

\footnotetext{
${ }^{1}$ Following convention I write the proposition that $\mathrm{p}$ as ' $<\mathrm{p}>$ '. I remain neutral on what the primary bearers of truth are supposed to be, although I mostly speak of 'propositions' and 'truths'.

${ }^{2}$ For instance, (Mellor 2003; Rodriguez-Pereyra 2005) reject truthmaker-maximalism, and (Melia 2005; Schaffer 2008, 2010) deny that the truthmaking relation is necessitation.

${ }^{3}$ Armstrong and C.B. Martin use truthmaking to this effect, see (Armstrong 2004). Regarding presentism, see (Keller 2004; Parsons 2005; Rhoda 2009). For scepticism about this use of truthmaking, see (Tallant 2009).

${ }^{4}$ For a critique of the last application, see (Schaffer 2008).

${ }^{5}$ For a detailed critique of Schaffer's account of truthmaking, see (Fisher 2014).

${ }^{6}$ If required, suppose the content of ' $S$ ' is fundamental or that ' $S$ ' is about something fundamental.

7 Thanks to José Benardete, Kevan Edwards, Kendall Englund, Peter Forrest, André Gallois, Mark

Heller, Kris McDaniel, Hugh Mellor and Joshua Spencer for comments on earlier versions of this paper. I am also grateful to an anonymous referee of this journal for excellent comments and suggestions. Lastly, I thank the audience at Dalhousie University, 19 October 2012.
}

\section{References}

Armstrong, D. M. (1997) A World of States of Affairs (Cambridge: Cambridge University Press). -. (2004) Truth and Truthmakers (Cambridge: Cambridge University Press). Bennett, Karen. (2011) 'By Our Bootstraps'. Philosophical Perspectives 25(1): 27-41. Cameron, Ross P. (2008a) 'Truthmakers and Modality'. Synthese 164(2): 261-80.

—. (2008b) 'Truthmakers and Ontological Commitment'. Philosophical Studies 140(1): 1-18.

-. (2008c) 'Truthmakers, Realism and Ontology'. In R. Le Poidevin (ed.), Being: Developments in Contemporary Metaphysics (Cambridge: Cambridge University Press), pp. 107-28.

—. (2010) 'From Humean Truthmaker Theory to Priority Monism'. Nô̂s 44(1): 178-98.

-. (forthcoming) 'Truthmakers'. In M. Glanzberg (ed.), The Oxford Handbook of Truth (Oxford: Oxford University Press). 
Cheyne, Colin, and Pigden, Charles. (2006) 'Negative Truths from Positive Facts'. Australasian Journal of Philosophy 84(2): 249-65.

Correia, Fabrice. (2011) 'From Grounding to Truth-Making: Some Thoughts'. In A. Reboul (ed.), Philosophical Papers Dedicated to Kevin Mulligan (Genève: URL http://www.philosophie.ch/kevin/festschrift/).

David, Marian. (2005) 'Armstrong on Truthmaking'. In H. Beebee and J. Dodd (ed.), Truthmakers: The Contemporary Debate (Oxford: Clarendon Press), pp. 141-59.

Davidson, Donald. (1984) Inquiries into Truth and Interpretation (Oxford: Clarendon Press).

Fisher, A. R. J. (2014) 'Priority Monism, Partiality, and Minimal Truthmakers'. Philosophical Studies doi: 10.1007/s11098-014-0314-z.

Forrest, Peter, and Khlentzos, Drew. (2000) 'Introduction: Truth Maker and Its Variants'. Logique et Analyse 43(169-170): 3-15.

Jackson, Frank. (1998) From Metaphysics to Ethics: A Defence of Conceptual Analysis (Oxford: Clarendon Press).

Keller, Simon. (2004) 'Presentism and Truthmaking'. In D. Zimmerman (ed.), Oxford Studies in Metaphysics vol. 1 (Oxford: Clarendon Press), pp. 83-104.

Korman, Daniel Z. (2013) 'Fundamental Quantification and the Language of the Ontology Room'. Noûs doi: 10.1111/nous.12027.

Melia, Joseph. (2005) 'Truthmaking without Truthmakers'. In H. Beebee and J. Dodd (ed.), Truthmakers: A Contemporary Debate (Oxford: Oxford University Press), pp. 67-84.

Mellor, D. H. (2003) 'Replies'. In H. Lillehammer and G. Rodríguez Pereyra (ed.), Real Metaphysics: Essays in Honour of D. H. Mellor (London: Routledge), pp. 212-38.

-. (2009) 'Truthmakers for What?'. In H. Dyke (ed.), From Truth to Reality: New Essays in Logic and Metaphysics (London: Routledge), pp. 272-90.

Mulligan, Kevin. (2006) 'Facts, Formal Objects and Ontology'. In A. Bottani and R. Davies (ed.), Modes of Existence: Papers in Ontology and Philosophical Logic (Frankfurt: Ontos Verlag).

Parsons, Josh. (2005) 'Truthmakers, the Past, and the Future'. In H. Beebee and J. Dodd (ed.), Truthmakers: The Contemporary Debate (Oxford: Clarendon Press).

Rhoda, Alan. (2009) 'Presentism, Truthmakers and God'. Pacific Philosophical Quarterly 90(1): 41-62.

Rodriguez-Pereyra, Gonzalo. (2005) 'Why Truthmakers'. In H. Beebee and J. Dodd (ed.), Truthmakers: The Contemporary Debate (Oxford: Clarendon Press), pp. 17-31.

Rosen, Gideon. (2010) 'Metaphysical Dependence: Grounding and Reduction'. In B. Hale and A. Hoffman (ed.), Modality: Metaphysics, Logic, and Epistemology (Oxford: Clarendon Press), pp. 109-35.

Schaffer, Jonathan. (2008) 'Truthmaker Commitments'. Philosophical Studies 141(1): 7-19.

-. (2009) 'On What Grounds What'. In D. Chalmers, D. Manley and R. Wasserman (ed.), Metametaphysics: New Essays on the Foundations of Ontology (Oxford: Clarendon Press), pp. 347-83.

—. (2010) 'The Least Discerning and Most Promiscuous Truthmaker'. Philosophical Quarterly 60(239): 307-24.

Sider, Theodore. (2011) Writing the Book of the World (Oxford: Clarendon Press).

Smith, Barry, and Brogaard, Berit. (2000) 'A Unified Theory of Truth and Reference'. Logique et Analyse 43(169-170): 49-93.

Tallant, Jonathan. (2009) 'Ontological Cheats Might Just Prosper'. Analysis 69(3): 422-30. 